\title{
The Effect Of Sulfur Waste And ABS On Asphalt Cement Properties
}

\author{
A. R. I. Al-Hadidy and A. T. Hameed \\ Civil Engineering Department, University of Mosul, Mosul/Iraq
}

\begin{abstract}
Nineveh is one of the Iraqi provinces $400 \mathrm{~km}$ north Baghdad capital and having an industrial company for sulfur production. This company produces nearly $20-25 \%$ of the total production as waste materials. This research investigates the ways of recycling the sulfur waste (SW) in solving the higher cost problem coming from import of waterproofing materials and presents information on the program and laboratory test data. Materials used in test program included 40/50 asphalt cement, Alkyl benzene sulfonate (ABS) and sulfur waste (SW). Five SW contents $0,1,3,5$ and $7 \%$, and $1 \%$ of ABS in terms of asphalt cement by weight were used. Tests including physical properties, compatibility, storage stability, aging properties, temperature susceptibility and water permeability were carried out in accordance with the ASTM procedure. The test results revealed that $\mathrm{SW}$ is a reliable material for paving asphalt cement and being readily available can be widely used in water proofing construction materials, and this offers profound engineering and economic advantages.
\end{abstract}

Keywords: Sulfur waste, Alkylbenzene sulfonate, Asphalt, Modifier, Water proofing material.

$$
\begin{aligned}
& \text { تأثير فضلات الكبريث والاكيل بنزين سلفونيت على خصائص الاسفلت } \\
& \text { عبد الرحيم إبراهيم الحديدي و أيمن طالب حميد } \\
& \text { ـ قسم الهندسة المدنية ـ كلية الهندسة - جامعة الموصل }
\end{aligned}
$$

\section{الخلاصة}

تمتلك محافظة نينوى شركة لصناعة الكبريت. تنتج هذه الثركة ما يقارب 20 إلى 25\% من من الناتج الكلي

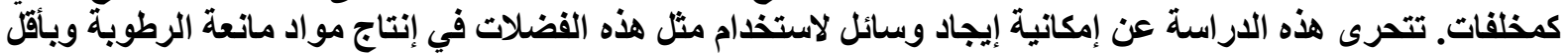

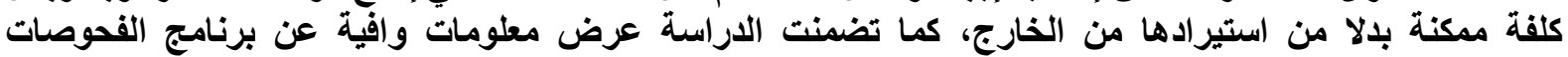

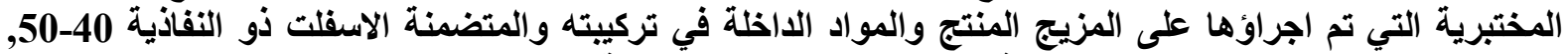

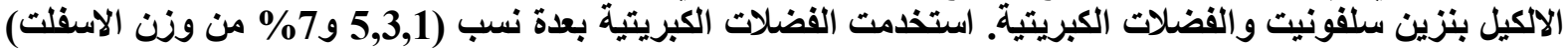

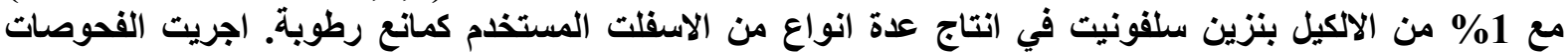

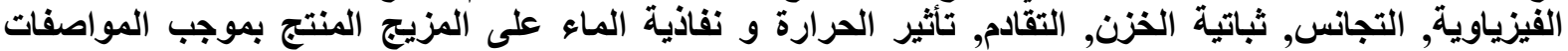

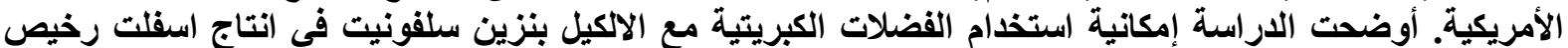

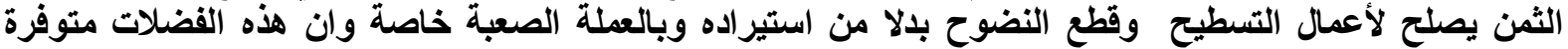

الكلمات الدالة: فضلات الكبريت: الكيل بمزين سلفونيت: اسفلت: محنات: مواد مانعة رطوبة. 


\section{Introduction:}

Roofing materials (asphalt and joint sealant) are regarded as one of the important primary materials used in the field of civil engineering work. Their selection must always be a matter of compromise between price and performance. It is speculated that the current annual worldwide consumption of waterproofing materials is over 120 million tons [1]. Asphalt and joint sealant are used in civil engineering work or in road paving construction because it is a strong cement, readily adhesive, highly waterproof, and durable. It is because of these superior qualities that asphalt and joint sealant are so widely used in the field of civil engineering work.

The behavior of asphalt cement in service is governed by their initial engineering properties as well as by the mechanical and environmental conditions to which they are subjected [2]. Available asphalt from refinery is too soft for roofing in high temperature areas in summer, and too brittle for a subzero temperature in winter in various parts of the country. The durability of asphalts is largely influenced by its chemical composition. It has been observed that Iraqi asphalts obtained from imported as well as indigenous crude contain 9 to $29 \%$ asphaltenes, 20 to $41 \%$ polar aromatics, 21 to $41 \%$ nephthene aromatics and 8 to $16 \%$ saturates [3]. The control of chemical composition of asphalt cement is a difficult task for refineries.

The available asphalts are not ideal for dam proofing and waterproofing applications. The waxy asphalt cement from indigenous crudes contains 8 to $16 \%$ wax, which causes softening of binder at high temperature and reduction in adhesion. Under these situations, it is essential to modify the asphalt cement using modifiers to improve its engineering properties. Among various types of modifiers, polymers are probably the most promising. Despite the large number of polymeric products, relatively few are suitable for modification of asphalt cement and are compatible with asphalt cement [4].

Polymer-modified asphalt binders are known to have better engineering properties. Improved properties have been reported in major areas of pavement deteriorations; high temperature rutting resistance, low temperature thermal and fatigue crack reduction etc. $[1,3$, 5-17].

Because the polymer modifiers that have been employed beneficially as asphalt modifiers are rather expensive, a need exists for alternative, lower-cost modifiers that nonetheless impart improved properties comparable to those achieved by using the more expensive polymers.

Nineveh is one of the Iraqi provinces (400 km north Baghdad capital) having an industrial company for sulfur production. This company produces nearly $20-25 \%$ of the total production as waste materials. Sulfur waste (SW) is a fine gray to green powder mainly composed of sulfur, carbon and ash. It consists of 88 to 90 percent sulfur, 10 to 12 percent carbon, and small amount of ash (0.1 percent) [18].

The melting point of SW varies depending on the sulfur concentration and ranges between 140 to $145 \mathrm{oC}$. In general, the sulfur waste specific gravity ranges between 2.03 to 2.215. Most used SW cannot be directly recycled and must be discarded. Although it is possible to incinerate waste sulfur to recover significant heat energy, most waste sulfur is 
disposed of by burial in landfills. Like most materials that are disposed of in landfills, waste sulfur does not degrade. Although estimates vary, the amount of waste sulfur produced and landfilled annually is roughly 7,000 to 20,000 tons. At a landfill disposal cost of at least $\$ 95 /$ ton, this quantity of discarded waste sulfur costs the sulfur industry between $\$ 665,000$ and $\$ 2000,000$ per year. This makes it especially desirable to develop alternative, more costeffective methods for disposing of this material, and particularly methods for recycling it.

The present study concentrated on investigating the use of SW with asphalt cement to manufacture an economically water proofing and damp proofing asphalt cement. Their selection must always be a matter of compromise between price and performance. Among the reasons for the popularity of manufacture of SW asphalt cement as waterproofing materials are the wide range of the useful physical properties, the low cost and the ease of processing.

From a technological stand point, the typical specifications for water proofing and damp proofing asphalt cement include: The ability to prevent the surface of various shapes and types from water leakage; economical aspects, and ease of use.

The aims of this paper are: (1) to use SW as a modifier with 40/50 paving asphalt in the manufacture of waterproofing asphalt cement; (2) Raising waterproofing asphalt cement performance to sustain Iraqi continental climate; and (3) Diminishing costs by applying cheap raw materials. Besides investigating the development of water proofing asphalt cement, the experimental work aimed at achieving one or both of the following objectives: (1) to determine the physical properties of SW-modified asphalt binder (SWMAB) with and without Alkyl benzene sulfonate (ABS) as a catalyst and compare the results with 40/50 penetration grade asphalt cement; (2) to evaluate temperature susceptibility of SWMAB with and without ABS and compare the results with asphalt cement; and (3) to optimize the shortterm aging performance of SWMAB with and without ABS by proper selection of SW concentration.

\section{Experiment}

40-50 penetration grade asphalt was selected for this study. Some properties of this asphalt are listed in Table 1.

Asphalt has high asphaltene content (32.65\%). This asphalt is a less compatible (gel type), and is usually considered the type, which have been used widely in the highway construction projects in Nineveh Government (400km North Baghdad Capital). Note that compatibility is a compositional property that correlates with various physical properties [3].

Asphalt has long been classified as gel or sol type. Gel-type asphalts usually exhibit pronounced non-Newtonian behavior, whereas sol-type asphalts are more Newtonian. Geltype asphalts generally contain large amounts of asphaltenes, and sol-type asphalts are characterized by low asphaltene content. Using the classical asphalt science terminology, soltype asphalts are more compatible, while gel-type asphalts are less compatible [3]. Less compatible (gel-type) asphalt is known to be highly susceptible to oxidative age hardening. While highly compatible (sol-type) asphalt is not susceptible to oxidative age hardening. It is anticipated that the SW will dissolve when interacting with asphalt. 


Table 1 Physiochemical properties of asphalt cement
\begin{tabular}{|l|c|c|}
\hline Property & Result & $\begin{array}{c}\text { ASTM } \\
\text { limits }\end{array}$ \\
\hline Penetration $\left(25^{\circ} \mathrm{C}, 100 \mathrm{~g}, \mathrm{dmm}\right)$ & 42 & $40-50$ \\
\hline Softening point, ${ }^{\circ} \mathrm{C}$ & 54 & $50-58$ \\
\hline Ductility $\left(25^{\circ} \mathrm{C}, \mathrm{cm}\right)$ & $150^{+}$ & $100 \mathrm{~min}$ \\
\hline Specific gravity & 1.053 & $1.01-1.06$ \\
\hline Flash point, ${ }^{\circ} \mathrm{C}$ & 263 & $240 \mathrm{~min}$ \\
\hline Loss of heat and air, \% & 0.25 & $0.2 \mathrm{max}$ \\
\hline Ashaltene, $\%$ & 32.65 & --- \\
\hline Solubility, $\%$ & 99.21 & 99 min \\
\hline Residue ductility $\left(25^{\circ} \mathrm{C}, \mathrm{cm}\right)$ & 142 & --- \\
\hline Residue penetration, $\%$ of original & 88 & --- \\
\hline $\begin{array}{l}\text { Increase of softening point after } \\
\text { TFOT, }{ }^{\circ} \mathrm{C}\end{array}$ & 2 & --- \\
\hline
\end{tabular}

The SW is a residual material of sulfur production unit. It was obtained from AlMeshrak state company (30 km north of Mosul). The physiochemical properties of these materials are shown in Table 2.

Table 2 Physiochemical properties of sulfur waste

\begin{tabular}{|l|c|}
\hline Element & \% wt. \\
\hline Sulfur & $88-90$ \\
\hline Carbon & $10-12$ \\
\hline Ash & 0.1 \\
\hline sp. gr. & 2.03 \\
\hline
\end{tabular}

The ABS was brought from al-Kornesh market in Mosul city. The price of this material was $0.133 \$ / \mathrm{kg}$. The physiochemical properties of ABS are shown in Table 3.

Two groups of SWMAB were prepared. The first group was labelled as $\mathrm{SWMAB}_{0}$. The second group was then treated with $1 \%$ ABS (by wt. of asphalt) as catalyst and labelled as $\mathrm{SWMAB}_{1}$. Eight different concentrations of SW-modified asphalt (SWMA) were thus prepared by first heating the asphalt to $140^{\circ} \mathrm{C}$. Upon reaching $140^{\circ} \mathrm{C}$, a weighed amount of SW with and without ABS (1, 3, 5 and $7 \%$ by weight of asphalt) was slowly added while mixing at $140^{\circ} \mathrm{C}$ using a slow-speed stirrer, and blending was done for a period of 8-12 minutes to obtain a homogeneity binder. Hence, it should be mentioned that the ABS percentage was chosen based on the previous study adapted by the author [19]. After completion, the SWMAB was removed from the can, divided into small pans, cooled to room temperature, sealed with aluminum foil, and stored for the following tests: 
Table 3 Physiochemical properties of ABS

\begin{tabular}{|l|c|}
\hline Property & Test result and unit \\
\hline $\begin{array}{l}\text { Color } \\
\text { unit }\end{array}$ & $\left(\mathrm{CH}_{3}\right)_{9}$ \\
\hline Price & \\
\hline
\end{tabular}

- Physical tests such as penetration, ductility, softening point ... etc.

- Temperature susceptibility.

- Short term aging using thin film over test (TFOT), which simulates the aging effect of the asphalt mixture production and construction

- Compatibility test

- Permeability test

All tests followed the ASTM [20] standards.

\section{RESULTS AND DISCISSION Physical tests}

Due to the difference in the solubility parameter and density between SW and asphalt, phase separation would take place in SW-modified asphalts during storage at elevated temperatures or at high mixing temperatures. Droplets of the SW melt dispersed in asphalt are usually accumulated at a high temperature and static state due to the recrystalization of sulfur. If a mixture of SW and asphalt is kept at high temperature, the SW will separate out from the asphalt, which will result in the difference in properties. The physical properties of $\mathrm{SW}$-asphalt binders with and without ABS were evaluated and the results are presented in Table 4.

Table 4 The main properties of SWMABs

\begin{tabular}{|c|c|c|c|c|c|c|c|}
\hline \multirow{2}{*}{$\% \mathrm{SW}$} & \multicolumn{2}{|c|}{ Penetration } & \multicolumn{2}{|c|}{ Ductility } & \multirow{2}{*}{$\begin{array}{l}\text { Flash point } \\
{ }^{\circ} \mathrm{C} \\
\mathrm{SWMAB}_{1}\end{array}$} & \multicolumn{2}{|c|}{$\begin{array}{c}\text { Softening point } \\
{ }^{\circ} \mathrm{C}\end{array}$} \\
\hline & SWMAB $_{0}$ & SWMAB $_{1}$ & $\mathrm{SWMAB}_{0}$ & $\mathrm{SWMAB}_{1}$ & & $\mathrm{SWMAB}_{0}$ & SWMAB $_{1}$ \\
\hline 0 & 42 & 42 & $150^{+}$ & $150^{+}$ & 263 & 54 & 54 \\
\hline 1 & 36.8 & 39 & 111 & 127 & 259 & 52 & 58 \\
\hline 3 & 27 & 31.8 & 86 & 102 & 241 & 49 & 64 \\
\hline 5 & 22.2 & 24.6 & 78 & 87 & 219 & 61 & 69.2 \\
\hline 7 & 16.9 & 19 & 62 & 69 & 202 & 66 & 78 \\
\hline \begin{tabular}{|l|} 
ASTM \\
D312 \\
\end{tabular} & \multicolumn{2}{|c|}{$25-50$} & \multicolumn{2}{|c|}{$10 \mathrm{~min}$} & $232 \mathrm{~min}$ & \multicolumn{2}{|c|}{$63-77$} \\
\hline $\begin{array}{l}\text { ASTM } \\
\text { limits } \\
\end{array}$ & \multicolumn{2}{|c|}{$40-50$} & \multicolumn{2}{|c|}{$100^{+}$} & $>240$ & \multicolumn{2}{|c|}{$50-58$} \\
\hline SCRB[20] & \multicolumn{2}{|c|}{$40-50$} & \multicolumn{2}{|c|}{$100^{+}$} & - & \multicolumn{2}{|c|}{51.62} \\
\hline
\end{tabular}


From this Table, it can be seen that the modified asphalts with varying SW content show good properties after reaction with $\mathrm{ABS}$. The ductility values of $\mathrm{SWMAB}_{0}$ and $\mathrm{SWMAB}_{1}$ at $3 \% \mathrm{SW}$ are 86 and 102, respectively. For these two modified asphalts the penetration values are 27 and 32, respectively. The results also revealed that the softening point of virgin asphalt modified by $3 \% \mathrm{SW}$ with the addition of $1 \%$ ABS raised by $19 \%$, whereas, it decreased by $9 \%$ with the absence of ABS. These results confirm that the physical properties, elasticity, compatibility and storage stability of SW-modified asphalt had been improved effectively with the addition of $1 \%$ ABS (by wt. of asphalt) due to the formation of a chemically crosslinked network in the modified binders, and the photomicrographs in Figure 7 insure these results.

\section{Temperature susceptibility}

The temperature susceptibility of asphalt binders is quantified by penetration index (PI) using the following equation mentioned by Yang [21]:

$$
\begin{aligned}
& \text { pentrationindex }(P . I)=\frac{20-500 A}{1+50 A} \\
& A=\frac{\log (\text { Pen.@ } T)-\log 800}{T-T_{R \& B}}
\end{aligned}
$$

Where

$\mathrm{T}=$ Testing temperature $\&$

$\mathrm{T}_{\mathrm{R} \& \mathrm{~B}}=$ Ring and Ball softening point.

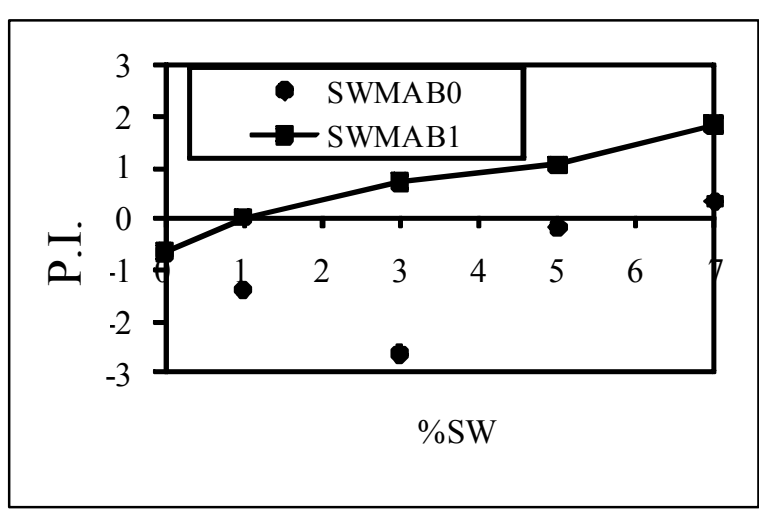

Fig. 1 P.I. of SWMABs

Calculated values of PI for SW-modified asphalt and asphalt cement are given in Figure 1. A higher value of PI indicates the lower temperature susceptibility of binder. From this Figure, it can be observed that the values of P.I. for virgin, 3\% $\mathrm{SWMAB}_{0}$ and $3 \%$ $\mathrm{SWMAB}_{1}$ samples are $-0.644,-2.621$ and +0.7307 , respectively. This significant fact demonstrates that SW will lead to make this binder less susceptible to temperature and more favorable for hot climates with the addition of ABS.

\section{Aging susceptibility of SW binders}

Fig. 2 and 3 show the ductility and softening point properties of aged SWMAB1. From these Figures, it can be seen that ductility decreases, while softening point increases. Moreover the values of ductility remain $\left(100^{+}\right)$up to $1 \% \mathrm{SW}$ content.

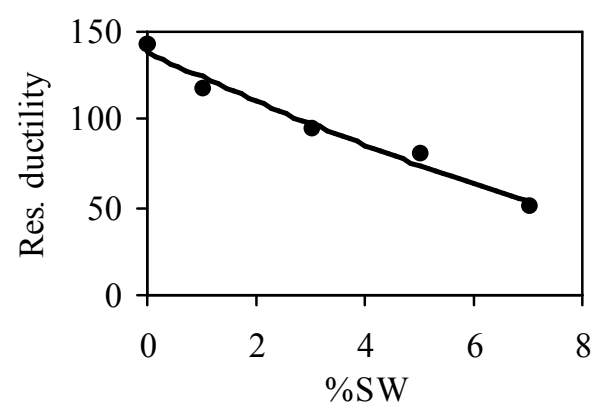

Fig. 2 Ductility of SWMAB 1

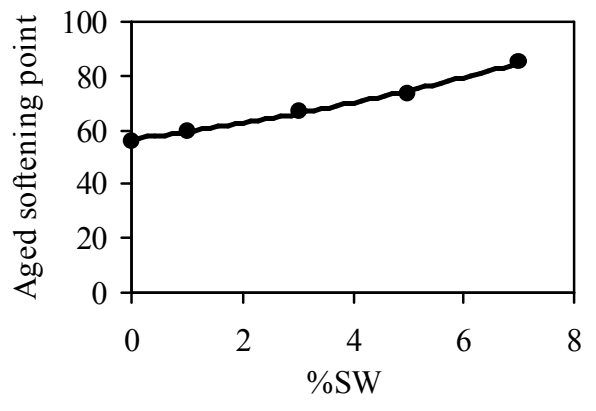

Fig. 3 Softening point of SWMAB 
Fig. 4 shows that the percent loss of SW binders increases as the SW content increases. This is related to that SW occupied much of the volume of the total mixture, which leads to increase in loss by dehydrogenation and oxidation of asphalt in the mixture. The results also indicate that the percentages loss of $\mathrm{SWMAB}_{1}$ less than those obtained with $\mathrm{SWMAB}_{0}$.

The hardening of $\mathrm{SWMAB}_{1}$ binders was determined by the penetration of residue after exposure to heat and air as shown in Fig. 5. Aging was measured by aging index using the following equation:

Aging index $=$ Residue penetration after aging at $25^{\circ} \mathrm{C} /$ original penetration at $25^{\circ} \mathrm{C}$

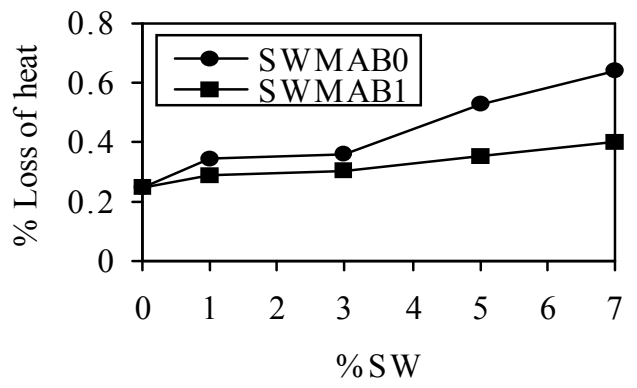

Fig. 4 Percent loss of heat and air of SWMABs

It can be seen from Fig. 6 that aging index increases slightly at 3\% SW content due to the increase in bonds between SW and asphalt resulting in the prevention of the brittleness of the resultant binder.

\section{Sulfur waste-Asphalt compatibility}

After curing the SWMAB0 and $\mathrm{SWMAB}_{1}$ binders into a glass tube in an oven at $140^{\circ} \mathrm{C}$ for 48 hours, then taken out, and cooled to room temperature. 5-10 mg modified asphalt was then heated and slowly pressed between two glass slides. The sample morphology (compatibility) was observed using an optical microscope with a hot plate. Morphology was monitored at a magnification of $400 \mathrm{X}$ at $140^{\circ} \mathrm{C}$ and as shown in Fig. 7. The photomicrographs demonstrate that $3 \% \mathrm{SW}$ is well dissolved in $\mathrm{SWMAB}_{1}$ than $\mathrm{SWMAB}_{0}$ at temperature of $140^{\circ} \mathrm{C}$ and the ductility values in Table 4 insure these results.

\section{Permeability test}

Permeability test was conducted on $30 \times 30 \mathrm{~cm}$ concrete slabs. The slabs were covered with a $3 \mathrm{~mm}$ of asphalt modified with different sulfur waste contents, then these slabs were placed in a controlled water bath at $70^{\circ} \mathrm{C}$ for 12 hours. These conditions were designed to simulate typical summer temperatures in Iraq and then the slabs were removed from water bath for density measurements.

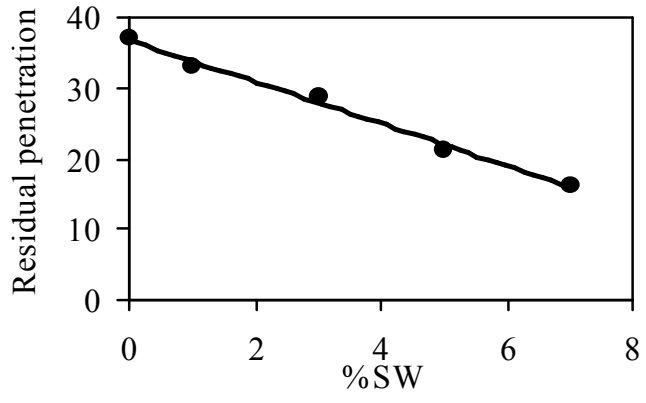

Fig. 5 Residual penetration of SWMAB

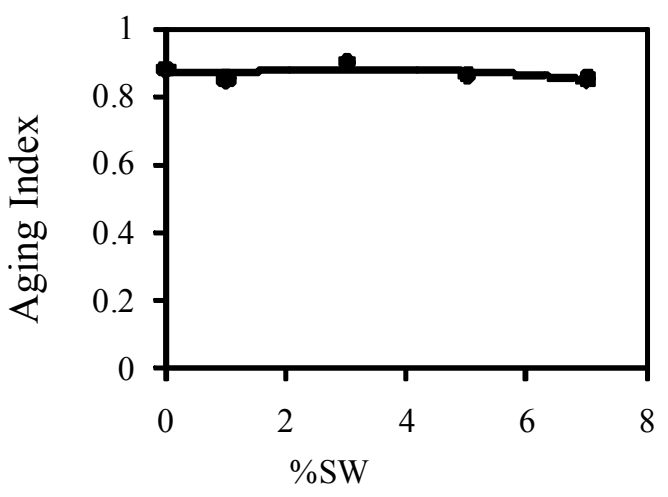

Fig. 6 Aging index of SWAB 

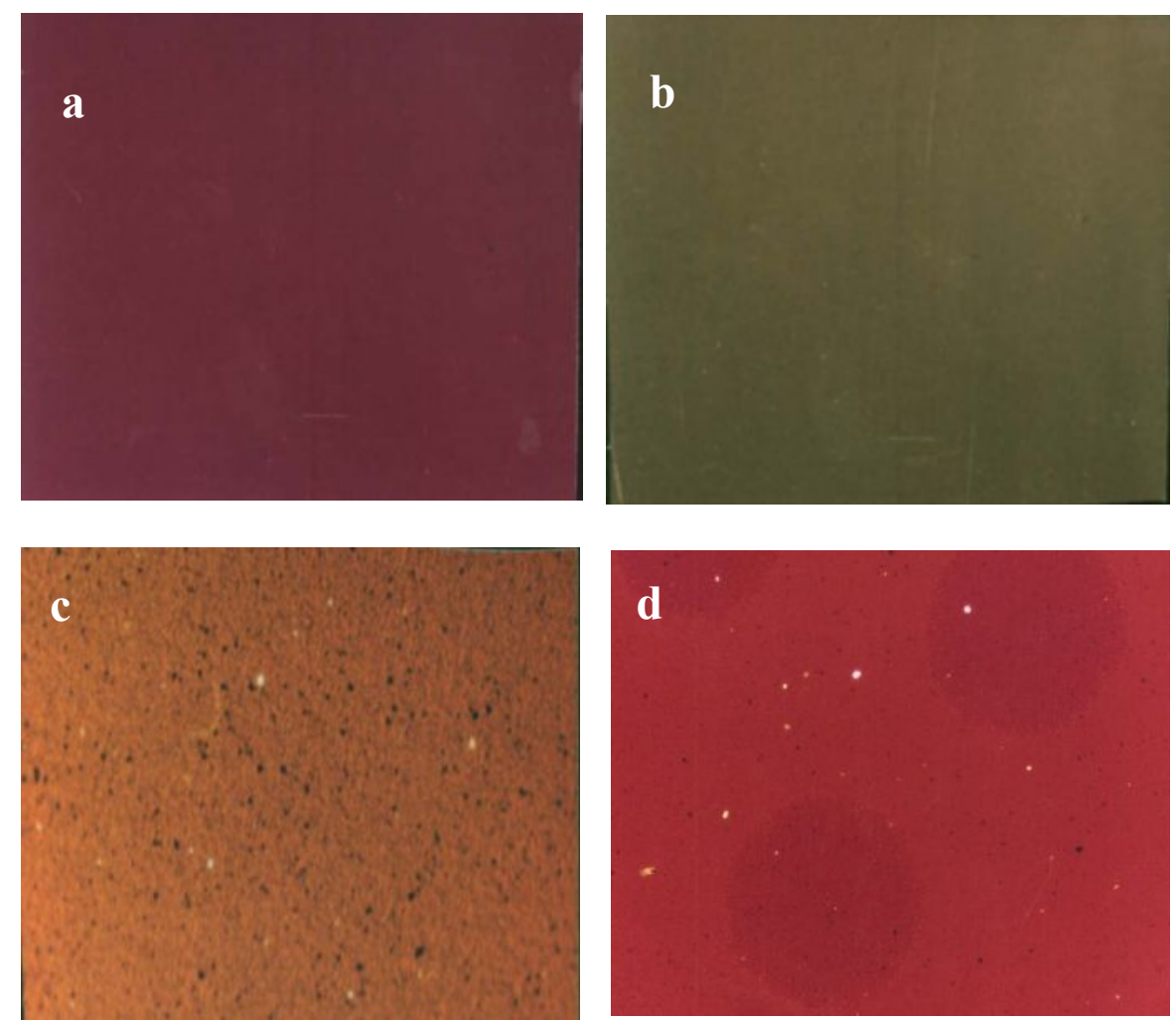

Fig. 7 Photomicrographs of SWMABs

$\left(a=0.0 \%, b=3 \% \text { SWMAB } 1, c=5 \% S W M A B_{1} \& d=3 \% S_{1} \text { SWAB }\right)_{0}$

Fig. 8 illustrates the difference in density measurements for $\mathrm{SWMAB}_{1}$. From this Figure it can be seen that no leakage was pronounced up to $3 \% \mathrm{SW}$ contents, which indicates that SW was completely dissolved in asphalt. Recrystalization of SW was pronounced after this certain content and as a result water leakage occurred.

\section{Economical Consideration}

Table 5 demonstrates economical consideration through calculating the cost of the

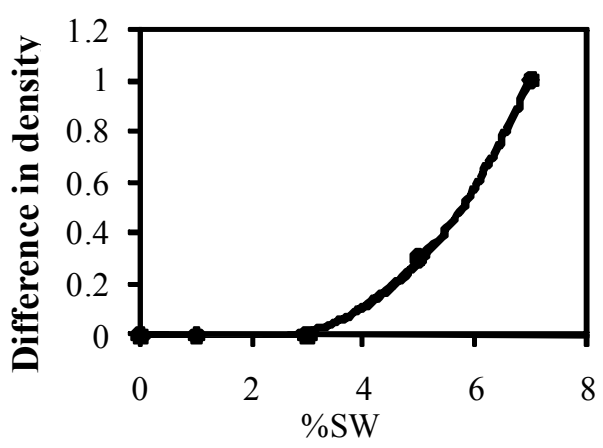

Fig. 8 Difference in density measurements produced waterproofing asphalt (asphalt mastic).

Table 5 Cost of materials used in the production of asphalt mastic

\begin{tabular}{|l|c|}
\hline Introduced materials & Cost in \$ per ton \\
\hline Asphalt 40/50 & 50 \\
\hline Sulfur Waste & 15 \\
\hline Alkyl Benzene Sulfonate & 133.4 \\
\hline Mixing and packing & - \\
\hline Total (without Mixing and packing) & 64.792 \\
\hline
\end{tabular}




\section{Conclusions:}

Based on the testing and analysis presented, the results of the study warrant the following conclusions:

1.The physical properties of modified asphalt with $3 \% \mathrm{SWMAB}_{1}$ including softening point, penetration, flash point and ductility are complies with the ASTM D312 specifications for asphalt used in dampproofing and waterproofing type II, and paving construction.

2.The morphology observation confirms that the compatibility, elasticity and storage stability of SW-modified asphalt can be improved in the presence of ABS.

3.Penetration at $25{ }^{\circ} \mathrm{C}$ will generally decrease as $\mathrm{SW}$ content increases, which indicates an improved shear resistance in medium to high temperatures.

4.The softening point of virgin asphalt modified by $3 \% \mathrm{SW}$ with the addition of $1 \% \mathrm{ABS}$ raised by $19 \%$, whereas, it decreased by $9 \%$ with the absence of ABS, which indicates improvement in resistance to deformation.

5.A $3 \% \mathrm{SWMAB}_{1}$ binder has a very fine network structure at a magnification of 400 , as shown in Fig $7 \mathrm{~b}$. This fact demonstrates that $\mathrm{SWMAB}_{1}$ binders are more compatible and can be stored for future use.

6.It was found that the penetration index values for $\mathrm{SWMAB}_{1}$ binder are less than those for virgin and $\mathrm{SWMA}_{0}$ binders, which indicated that this binder less susceptible to temperature and more favorable for hot climates; and

7.SW-modified asphalt without ABS was unstable and had phase separation at high temperature, as shown in Fig. $7 \mathrm{~d}$.

8.The result indicated that modified asphalt with SW can be used as a water proofing and damp proofing material and it is much cheaper (see Table 5).

\section{Refernces}

1. [1] Ostermeyer, Larry F., US.Pat.5221703; 1993.

2. [2] Awanti S.S., Amarnath M. S, and A. Veeraragavan (2008). "Laboratory Evaluation of SBS Modified Bituminous Paving Mix”. J Mater Civil Eng, 20(4):327330.

3. [3] Shin-Che Huang (2008). Rubber Concentrations on Rheology of Aged Asphalt Binders. J. Mater. Civ. Eng., 20(3), 221-229.

4. [4] Lu, X., Isacsson, U., and Ekblad, J. (1999). "Phase separation of SBS polymer modified bitumens." J. Mater. Civ. Eng., 11(1), 51-57.

5. [5] Wardlaw, K. R., and Shuler, S. (1992). Polymer-modified asphalt binders. ASTM STP 1108, Philadelphia.

6. [6] Lewandowski LH. (1994). "Polymer modification of paving asphalt binders". Rubber Chemistry and Technology. 67(3): 447-80.

7. [7] Maccarrone, S., Holleran, G., and Gnanaseelan, G. P. (1995). "Properties of polymer-modified binders and relationship to mix and pavement performance". Asphalt Paving Technol., (64): 209-236.

8. [8] Hesp, S. A. M., Terlouw, T., and Vonk, W. C. (2000). "Low temperature performance of SBS-modified asphalt mixes". Asphalt Paving Technol., (69): 540568. 
9. [9] Hailong Jin, Guangtao, YongZhang, Yinxi Zhang, Kang Sun and Yongzhong Fan (2002). "Improved properties of polystyrene-modified asphalt through dynamic vulcanization". J.Polymer Testing., (21):633-640.

10. [10] Wen, G., Zhang, Y., Sun, K., Chen, Z. (2002). "Vulcanization characteristics of asphalt/SBS blends in the presence of sulphur". J Applied Polymer Science. 82, 989.

11. [11] Uddin, W. (2003). "Viscoelastic characterization of polymer-modified asphalt binders of pavement applications". Appl. Rheol., 13(4): 191- 199.

12. [12] Chaminda Wekumbura; Jiri Stastna; and Ludo Zanzotto (2007). "Destruction and recovery of internal structure in polymer-modified asphalts". J.Mat.Civil Eng., 19(3): 227-223.

13. [13] Chui-Te Chiu, and Li-Cheng Lu (2007). "A laboratory study on stone matrix asphalt using ground tire rubber". J. Construction and Building Materials. (21): 10271033.

14. [14] Punith V. S., A. Veeraragavan (2007), "Behavior of Asphalt Concrete Mixtures with Reclaimed Polyethylene as Additive". J. Mater. Civ. Eng., 19(6), 500-507.

15. [15] Al-Hadidy AI and Tan Yi-qiu (2009). "Effect of Polyethylene on Life of Flexible Pavements". J Construction and Building Materials, Vol.23, PP 1456-1464.

16. [16] Al-Hadidy AI and Tan Yi-qiu (2009). "Mechanistic Approach for Polypropylene-Modified Flexible Pavements" . J Materials and Design, vol.30, PP 1133-1140.

17. [17] Al-Hadidy AI and Tan Yi-qiu. "The effect of SBS on asphalt and SMA mixture properties ". J. Mat. Civil Engrg, under review.

18. [18] Firas S. Al-Golamie (2003) " The possibility of utilizing solid wastes from Mishraq sulphur purification processes" MS.C. Thesis, college of Science, Chemistry Dept, University of Mosul.

19. [19] Al-Hadidy AI. (2004)."Alkylbenzene Sulphonate as Additive in Asphalt Paving Mixtures".J.Engineering and Technology;No. 2,Vol.4,Baghdad,Iraq.

20. [20] American society for Testing and Materials (ASTM), (2000), Standard Specification, Section 4, Vol. 04-03.

21. [21] Yang H.H.(1993) "Pavement analysis and design" University of Kentucky, Jone Wily and Sons Inc. pp336,337,409,\&410.

22. [22] State cooperation of road and bridges (SCRB) (2003), Hot mix asphaltic concrete pavements. Iraqi standard specification. Ministry of Housing and construction. Department of Design and Study, section R9. 